\title{
ESTADO, LUTERANISMO E IMIGRAÇÃO NO BRASIL: PARA ALÉM DA EPOPEIA DOS PRIMEIROS PASTORES ALEMÃES
}

\author{
Rodrigo Pereira ${ }^{1}$ \\ Frederico Antonio Ferreira ${ }^{2}$
}

\begin{abstract}
Resumo: Objetivamos no presente artigo preencher uma lacuna referente ao início do processo de imigração e da relação desta com a implantação do Luteranismo no Brasil. Assim, o texto volta-se para a análise da relação entre o empreendimento estatal da colonização e a sua ação de prover aos imigrados os serviços religiosos protestantes. A partir da documentação do Arquivo Histórico (AHI), do Ministério das Relações Exteriores (MRE), no Rio de Janeiro, referente às trocas de correspondências entre a Representação Brasileira em Hamburgo e em Berlim com a Secretária dos Negócios Estrangeiros do Império do Brasil, entre as décadas de 1840 e 1860, poderemos observar como a inserção do Luteranismo consistiu em uma ação estatal e não meramente uma epopeia de pastores voluntários, que visavam atender seus irmãos na fé. Para tanto, observaremos dois casos, as Colônias de Santa Isabel (ES) e a de Petrópolis (RJ). Defende-se que o Estado Imperial adaptou suas ações, baseadas no Padroado Católico, na organização de um "Padroado Luterano" para os serviços religiosos aos imigrados.
\end{abstract}

Palavras-chaves: Luteranismo; Imigração alemã; Brasil; Padroado.

\section{STATE, LUTHERANISM AND IMMIGRATION IN BRAZIL: BEYOND THE EPIC OF THE FIRST GERMAN SHEPHERDS}

\begin{abstract}
In this article we aim to fill a gap regarding the beginning of the immigration process and its relationship with the implantation of Lutheranism in Brazil. Thus, the text turns to the analysis of the relationship between the state enterprise of colonization and its action to provide Protestant religious services to immigrants. From the documentation of the Historical Archive (AHI) of the Ministry of Foreign Affairs (MRE) in Rio de Janeiro, referring to exchanges of correspondence between the Brazilian Representation in Hamburg and Berlin with the Secretary of Foreign Affairs of the Empire of Brazil, Between the 1840s and 1860 s, we can see how the insertion of Lutheranism consisted of a state action and not merely an epic of voluntary shepherds, who sought to minister to their brethren in the faith. To do so, we will observe two cases, the Colonies of Santa Isabel (ES) and the one of Petrópolis (RJ). It is argued that the Imperial State adapted its actions, based on the Catholic Padroado, in the organization of a "Lutheran Padroado" for the religious services to the immigrants.
\end{abstract}

Keywords: Lutheranism; German Immigration; Brazil; Padroado.

\section{ESTADO, LUTERANISMO E INMIGRACIÓN EN BRASIL: ADEMÁS DE LA EPOPEYA DE LOS PRIMEROS PASTORES ALEMANES}

Resumen: Objetivamos en el presente artículo llenar una brecha referente al inicio del proceso de inmigración y de la relación de ésta con la implantación del Luteranismo en Brasil.

\footnotetext{
${ }^{1}$ Doutorando em Arqueologia no Museu Nacional da Quinta da Boa Vista - Universidade Federal do Rio de Janeiro (UFRJ). E-mail: rodrigopereira.cso@uol.com.br

${ }^{2}$ Arquivo Histórico do Itamaraty (RJ). Doutorando do Programa de Pós-Graduação em História da Universidade Federal Rural do Rio de Janeiro (UFRRJ). E-mail: arquivistafred@gmail.com
} 
Así, el texto se vuelve hacia el análisis de la relación entre el emprendimiento estatal de la colonización y su acción de proveer a los inmigrados los servicios religiosos protestantes. A partir de la documentación del Archivo Histórico (AHI), del Ministerio de Relaciones Exteriores (MRE), en Río de Janeiro, referente a los intercambios de correspondencias entre la Representación Brasileña en Hamburgo y en Berlín con la Secretaria de Asuntos Exteriores del Imperio de Brasil, entre las décadas de 1840 y 1860, podremos observar cómo la inserción del Luteranismo consistió en una acción estatal y no meramente una epopeya de pastores voluntarios, que pretendían atender a sus hermanos en la fe. Para eso, observaremos dos casos, las Colonias de Santa Isabel (ES) y la de Petrópolis (RJ). Se defiende que el Estado Imperial adaptó sus acciones, basadas en el Patronato Católico, en la organización de un "Patrono Luterano" para los servicios religiosos a los inmigrados.

Palabras claves: Luteranismo; Inmigración alemana; Brasil; Patroado.

\section{INTRODUÇÃO}

Para a memória desenvolvida sobre o processo de imigração alemã para o Brasil o tom de epopeia, sofrimento e morte são temas recorrentes. No caso do Espírito Santo chegouse a cunhar adágios populares sobre o processo entre o fim do século XIX e início do XX. Entre eles podemos destacar o "den ernest de told, den zweiten die not, den drietten das brot" - "aos primeiros a morte, aos segundos o sofrimento, aos terceiros o pão" (PEREIRA, 2014). Nele observamos como a narrativa criada pelos imigrados expressa uma leitura onde o sofrimento e agruras dão lugar a um sentimento de vitória e de conquista das terras para a agricultura e sustento da vida.

A relação entre a imigração alemã e a inserção do Luteranismo no Brasil é vista por uma série de autores como um processo que se confunde. Aos rincões das regiões Sul e Sudeste do Brasil se dirigiram pastores luteranos desejosos de auxiliar espiritualmente seus conterrâneos dos diversos reinos da atual Alemanha. Ao mesmo tempo, a historiografia sobre este processo centra-se entre 1824 a 1870 , voltando-se para os processos de movimento populacional e substituição de mão de obra, iniciada, oficialmente, em 1824, na então Província Rio Grande do Sul (DREHER, 1984).

Autores como Wagemann (1949), Roche (1968), Dreher (1970), Granzow (1975), Seide (1980), Steyer (1999), Grützmann (2002) e Rehfeldt (2003), por exemplo, não descartam o tom épico em seus textos ao se referirem aos religiosos e seus serviços nos primeiros anos das colônias de imigrados. A implantação do Luteranismo no Brasil teria se dado por religiosos independentes que, inserindo-se no processo de imigração, acompanharam seus conterrâneos. Caracteriza-se que o início do Protestantismo no país seria uma iniciativa 
de cunho pessoal e relativamente independente de medidas governamentais assessórias à implantação destes migrados no Brasil.

Dentre os mesmos autores (DREHER, 1984; STEYER, 1999; REHDEFELT, 2003; PEREIRA, 2015), destaca-se ainda a formação das organizações luteranas em solo nacional os Sínodos - a partir da década de 1880. Estes podem ser entendidos como direções nacionais ou regionais que visavam a organização religiosa dos pastores e congregações que se formavam ao longo do processo de imigração teutônica. Em especial dá-se maior visibilidade a formação das seguintes instituições: o Sínodo Rio-Grandense ${ }^{3}$, atuante no Rio Grande do Sul, em 1886; o Sínodo Evangélico Luterano Alemão do Missouri, Ohio e outros Estados ${ }^{4}$, de 1904, com maciça atuação inicial de pastores norte-americanos em todo Sul e Sudeste do Brasil; o Sínodo Luterano ou Gottenkasten Synode, de 1901, que abrangia os estados de Santa Catarina, Paraná, Espírito Santo, São Paulo e Rio de Janeiro ${ }^{5}$. Com exceção do sínodo de origem norte-americana, os demais se unirão em uma única organização eclesiástica em 1968, dando origem a Igreja Evangélica de Confissão Luterana no Brasil (IECLB) (DREHER, 1984; BACHMANN; BACHMANN, 1989, STEYER, 1999, REHDEFELT, 2003, PEREIRA, 2015; WEIDUSCHADT, 2015).

Objetivando preencher uma lacuna referente ao início do processo de imigração e da relação deste com a implantação do Luteranismo no Brasil, o presente artigo volta-se para a análise da relação entre o empreendimento estatal da colonização e a sua ação de prover aos imigrados os serviços religiosos protestantes, entre as décadas de 1840 a 1860, período anterior a criação dos referidos sínodos. A partir da documentação do Arquivo Histórico do Itamaraty (AHI), referente às trocas de correspondências entre a representação brasileira em Hamburgo e em Berlim com a Secretária dos Negócios do Estrangeiro do Brasil, poderemos observar como a inserção do Luteranismo consistiu em uma ação estatal e não meramente uma epopeia de pastores voluntários que visavam atender seus irmãos na fé. Defende-se que o Estado Imperial adaptou suas ações, baseadas no Padroado Católico, para a organização de um "Padroado Luterano", o que permitia a contratação de prelados na Alemanha, o custeamento de sua viagem e a remuneração pelos serviços prestados.

\footnotetext{
${ }^{3}$ Que alterou seu nome para Igreja Evangélica Alemã do Rio Grande do Sul (Sínodo Rio-grandense), em 1901.

4 Uma extensão do Sínodo Luterano formado no Estado Unidos com a migração teutônica para aquele país. Inicialmente o Sínodo tornou-se o $15^{\circ}$ distrito daquela organização, recebendo o nome de EvangelischLuterische Synode von Missouri, Ohio und anderen Sattaten. Renominado de Sínodo Evangélico Luterano do Brasil, em 1945 e novamente alterado seu nome, em 1954, para Igreja Evangélica Luterana do Brasil (IELB).

${ }^{5}$ Também denominado de Sínodo da Caixa de Deus, pois mantinha-se por meio de doações de alemães que as depositavam, ao final dos cultos, em caixas na saída das igrejas. Em 1911 ele passa a se denominar de Sínodo Luterano de Santa Catarina e Paraná - Sínodo do Brasil Central.
} 
O Padroado era um instituto existente desde o fim da Idade Média. Ele estabelecia que os reis de Portugal e Espanha teriam influência na instituição de padres e bispos nas dioceses de seus respectivos reinos, servindo de intermediários nas relações entre a Santa Sé e as referidas dioceses (VENTURA, 1997). Tal instituto foi estendido à monarquia brasileira após 1822. É valido destacar que, desde a constituição de 1824, o Império caracterizava-se como confessional católico, mas permitia cultos de outras denominações, desde que não houvesse a caracterização de um templo na fachada dos locais e que este ocorresse em ambiente doméstico (NEGRÃO, 2008). Pelo Padroado a nomeação, bem como o pagamento de salários, além da manutenção dos seminários de formação, eram prerrogativas do monarca (FAUSTO, 2012).

\section{A IMIGRAÇÃO ALEMÃ PARA O SUDESTE DO BRASIL}

A imigração europeia para o Brasil, conforme Pacheco (1978), teve duas funções: suprir a mão de obra escrava africana dedicada a produção de café para exportação e, ao mesmo tempo, povoar regiões desabitadas do império, em especial o interior do Sul e Sudeste do país. Além destas, para o caso do Rio de Janeiro, a capital do Império, destaca-se ainda a produção de alimentos para a crescente população (SZMRECSÁNYI; LAPA, 1996).

Ademais, a imigração servia ainda para uma política de embranquecimento da nação e pela crença de que apenas o elemento branco seria capaz de civiliza-la. Esta noção advinha de obras, como por exemplo, a do conde francês Joseph Arthur de Gobineau, L'émigration au Brésil, de 1874, na qual apresentava que, caso não houvesse a introdução do elemento europeu no país, a mestiçagem entre índios, negros e luso-brasileiros levaria à extinção da raça brasileira e o colapso do Império (SOUZA, 2013). Biógrafos de d. Pedro II, como Barman (2012), descrevem a relação pessoal do monarca com pesquisadores deste tema, além do costume do imperador em conhecer as teorias em voga na Europa durante seu reinado. Assim, a inserção da ideia de progresso do país pelo embranquecimento era, ao mesmo tempo, uma política nacional, mas também uma ação baseada nas próprias reflexões do imperador Bragança sobre o tema (BARMAN, 2012).

Para o historiador Eric Hobsbawn (1977), tudo aponta para que a população cooptada para a imigração fosse, quase que na totalidade, composta por camponeses recém-saídos da condição de servos. No que é hoje a atual Alemanha, a mão de obra rural fora colocada em uma base contratual pelas reformas do início do século XIX, os junkers, grandes proprietários 
de terras da Prússia, tal como diz Hobsbawn, "que por muito tempo tinham cultivado para o mercado de exportação com mão de obra servil, passaram a trabalhar como camponeses 'libertos' da servidão e da terra" (HOBSBAWN, 1977, p. 169). Estudos de Reinhard Bendix (1986), centrados nas análises de Max Weber sobre o trabalho rural na Alemanha neste período, mostram que o sociólogo alemão apontou que, em toda aquela área, e apesar de muitas variações locais, a força de trabalho rural dividia-se em duas categorias: a dos empregados contratados pelos proprietários de terra na base de contratos anuais e a dos contratados por dia:

Essa economia agrária tradicional fora tanto a imagem quanto a base da rígida organização política e militar do estado prussiano. Para o camponês, ou trabalhador rural do leste, era ponto pacífico que as ordens do proprietário eram emitidas no interesse de todos. (...) Assim, as propriedades eram centros de domínio que representavam uma tradição de ordens peremptórias e obediência absoluta (BENDIX, 1986, p. 54).

O declínio dessa a tradição, que havia sustentado a unidade política através da qual se conseguira a unidade do Reich, fez com que a influência pessoal e política dos junkers se tornasse "gradativamente mais pretensiosa, e tanto política quanto moralmente discutível" (BENDIX, 1986, p. 45). Os objetivos destes latifundiários eram de maximizar a produção nacional de cereais e exigia, para sua realização, que as grandes propriedades crescessem, ainda mais, em tamanho às custas das pequenas e médias propriedades ou terras anteriormente arrendadas a agricultores. Neste contexto, certas consequências tornaram-se inevitáveis, os conflitos de classes nos reinos do leste alemão se tornariam mais intensos. Em tais contextos, como mostra Bendix (1986),

Weber destacou que a transformação capitalista nas relações de trabalho no leste da Alemanha tendeu a baixar o padrão de vida dos trabalhadores (...) e mencionou a contratação frequente de mulheres, os alojamentos precários dos diaristas e suas famílias, e a falta de complementação salarial sob a forma de horticultura e de algumas cabeças de gado (BENDIX, 1986, p. 45).

Essa proletarização dos trabalhadores rurais foi agravada porque os empregadores recorreram à contratação de imigrantes poloneses e russos, uma decorrência só em parte da disposição desses estrangeiros a trabalhar por salários mais baixos, considerando que sua produtividade era inferior à dos trabalhadores alemães. Os trabalhadores poloneses e russos eram obedientes devido ao seu status precário. Eram também trabalhadores estritamente 
sazonais que podiam ser forçados a voltar para o outro lado da fronteira, liberando seus empregadores do peso de quaisquer obrigações financeiras ou administrativas. Analisando o enfraquecimento e o "desenraizamento" da população rural naquele período, Hobsbawn (1977) mostra que

O exemplo pomeraniano é sem dúvida extremo: posteriormente, neste século cerca de 2 mil grandes propriedades cobriam $61 \%$ da terra, 60 mil pequenas e médias cobriam o resto, e o restante da população não possuía terras (...) o enorme número dos que vegetavam na terra a que toda a história humana os prendia, mas que, se ela fosse produtivamente explorada, seriam um mero excedente populacional, tinha que ser arrancado de suas raízes para se mover livremente (HOBSBAWN, 1977, p. 169-171).

Segundo Marcos Antonio de Araújo, ministro do Brasil nas cidades de Hamburgo e Berlim entre as décadas de 1840 a 1870, esta oferta de mão de obra era a chance de que o Brasil precisava para remeter para a América do Sul levas de germânicos (AHI: 402/3/1). Estes, como acabamos de desenvolver, além de agricultores para o café, seriam capazes de fazer evoluir a "raça" brasileira devido à sua branquidade 6 .

Contudo, esta oferta de mão de obra sofria concorrência com outros países, da própria situação em que o empreendimento de imigração se direcionava no Brasil e da questão religiosa que se impunha - imigrantes luteranos em um país confessional católico. Em ofício datado de vinte e três de janeiro de 1848, a correspondência consular de Hamburgo para o Brasil já destacava a necessidade de uma lei que regulamentasse a concessão ou venda das terras devolutas e, ao mesmo tempo, a necessidade do respeito às diferentes denominações religiosas e o consequente casamento misto (AHI: 202/2/17). Na mesma missiva, o Ministro destacava que os Estados Unidos haviam promovido uma seleção de ofícios ou profissões como condicionais para a entrada dos imigrantes em seu território, o que poderia ser favorável ao Brasil ao arregimentá-los como imigrantes. Assim, concluía o ministro: "não falta gente de todas os offícios que queiram emigrar para o Brazil, mas o receio

\footnotetext{
${ }^{6} \mathrm{O}$ termo aqui tem os valores adotados por Frankemberg (2004, p. 321-313): "A branquidade é um lugar de vantagem estrutural nas sociedades estruturadas na dominação racial [...] a branquidade é um 'ponto de vista', um lugar a partir da qual nos vemos e vemos os outros e as ordens nacionais e globais; [...] a branquidade é comumente redenominada ou deslocada dentro das denominações étnicas ou de classe; [...] como lugar de privilégio, a branquidade não é absoluta, mas atravessada por uma gama de outros eixos de privilégio e subordinação relativos; estes não apagam nem tornam irrelevante o privilégio racial, mas o modulam ou modificam [...] a branquidade é produto da história e é uma categoria relacional. Como outras localizações raciais, não tem significado intrínseco, mas apenas socialmente construídos. Nessas condições, os significados da branquidade tem camadas complexas e variam localmente e entre os locais; além disso, seus significados podem parecer simultaneamente maleáveis e inflexíveis".
} 
de não encontrar terras devolutas que possa comprar, faz com que ella[s] tome[m] o caminho dos Estados Unidos" (AHI: 202/2/17).

Apenas no ano de 1847, conforme o ministro brasileiro, os Estados Unidos tinham recebido - saídos do Porto de Hamburgo - 63 navios com 7.383 imigrantes, enquanto o Brasil se fazia representar apenas com 5 navios e 763 imigrantes. Esta defasagem de $90 \%$ em relação ao total norte-americano era, ainda maior, se considerarmos os 271 germânicos que se direcionaram ao Brasil no ano anterior, conforme relata Marcos Antonio de Araújo (AHI: 202/2/17).

Entre os anos de 1848 até 1851, além da concorrência com os norte-americanos e de outros países como a Austrália e o Canadá, dois fatores se destacavam nos ofícios remetidos de Hamburgo quanto à imigração: a ausência de uma regularidade nos navios que se dirigissem ao Brasil e a entrada da Confederação Argentina na busca por alemães. Conforme o ministro, este país, em 1848, não tinha ainda representante oficial para a imigração em Hamburgo (AHI: 202/2/17), o que lhe permitiu informar ao Secretário dos Estrangeiros, Paulino José Soares de Souza, que "empregarei os meios ao meu alcance, afim de embaraçar algum [imigrante] que[,] por ventura[,] se queira verificar [para a Confederação Argentina]”. Ou seja, na falta de um agente de imigração para este local, o Brasil passava a tentar estorvar a ida dos alemães para o Sul do continente e convencê-lo a imigrar para o Brasil.

A ausência de um emissário da Confederação Argentina foi solucionada apenas em 1850, com a contratação de um alemão que havia se direcionado ao Rio Grande do Sul (Colônia de São Leopoldo), mas retornara para Hamburgo naquele ano, o Sr. Luiz (ou Louis) Bahre (AHI: 202/2/17). Inicia-se, conforme Marco Antonio de Araújo, um debate nos jornais de Hamburgo e Berlim com matérias que denegriam, ora o Brasil (redigidos pelo emissário argentino), ora a Confederação Argentina (escritos pelo representante brasileiro). Bahre, aproveitando-se de sua experiência no Sul do Brasil, fazia publicar artigos e notícias depreciativas quanto às colônias brasileiras. Por sua vez, o ministro, aproveitando-se de publicações locais de autores europeus sobre a imigração para o Brasil, utilizava-as em seus contra-ataques

[Os] combates [às] preguiças espalhadas pela Alemanha contra o Brazil e de informar os emigrantes a respeito das instituições brasileiras, direitos e deveres dos mesmos emigrantes, e de tudo em geral quanto lhes possa ser útil [...] devendo ser que esta obra seja realmente de utilidade para o Império, concorrendo para animar a emigração para ele e tornar mais conhecida na Europa as nossas instituições (AHI: 402/3/1). 
Apenas em 1852 é que essas querelas são arrefecidas, quando o Sr. Bahre é demitido de seu cargo. Contudo, em ofício datado de quatro de março daquele ano, Marco Antonio de Araújo informa a Paulino José S. de Souza, que as empresas de colonização norte-americanas ainda percebiam o Brasil como um concorrente quanto a captação de imigrantes alemães (AHI: 202/2/17), mesmo tendo um fluxo maior de pessoas para aquele país. Observando o aspecto financeiro das passagens entre a atual Alemanha e os Estados Unidos:

Para as cidades norte-americanas de Nova Orléans e Nova Iorque, a passagem custava, exatamente, a metade do preço de uma para a colônia de Blumenau na província de Santa Catarina, ou mesmo para as inúmeras colônias do Rio Grande do Sul. Sendo assim, era natural que houvesse entre os emigrantes uma preferência pela América do Norte, que chegou a receber mais de um milhão de indivíduos durante o século XIX (SIRIANI, 2005, p. 98).

Com esta perda de atratividade, conforme Marcos A. de Araújo, fazia-se necessário ao Brasil rever sua política de imigração (AHI: 402/3/4), pois além dos Estados Unidos, concorriam ainda na busca por mão de obra países como a Austrália, o Canadá e a colônia inglesa da África do Sul (AHI: 202/2/17). Caso nada fosse feito, o empreendimento imigratório poderia não obter os resultados esperados.

O processo de imigração brasileira pode ser dividido, conforme Hennig (1986), Witt (1996) e Delhaes-Guenther (1973), em três grandes momentos: de 1824 a 1848, com a imigração maciça de agricultores e pequenos artesãos; de 1848 a 1880, formada por alemães com maior instrução (uma pequena burguesia artesã e industrial); e de 1880 a 1890 que incluía pessoas de diversas profissões, além de populações teuto-russas, polonesas e balcânicas.

O empreendimento da colonização de determinadas regiões do Brasil, no início do século XIX, foi capitaneado pela criação de colônias coordenadas pelo governo imperial. Conforme instrução do Secretário dos Negócios do Império, Pedro de Araújo Lima (o Marques de Olinda), em 1847, o Brasil participou na criação de uma Sociedade de Emigração de Hamburgo, de $1849^{7}$, do qual era acionista (AHI: 403/3/3). Desta sociedade

\footnotetext{
${ }^{7}$ Sociedade formada pelo Governo Imperial e banqueiros e comerciantes de Hamburgo. Tinha por finalidade a exclusividade da ação de embarque de imigrantes para a Colônia Dona Francisca no Sul do Brasil. Apesar de algum sucesso inicial, a empresa veio a encerrar suas atividades em anos subsequentes devido a problemas de assentamento de imigrantes no Brasil (AHI: 403/3/3; RODOWICZ-OSWIECIMSKY, 1853).
} 
nasceu, por exemplo, a Colônia Dona Francisca, em Santa Catarina. Em anos anteriores, o exemplo da Colônia de São Leopoldo (1824), na Província do Rio Grande do Sul, não apenas iniciara o processo de transferência de mão de obra, mas indicava um campo promissor ao Governo Imperial quanto ao povoamento de determinadas regiões (SEYFERT, 1999). Ao longo do século XIX o empreendimento capitaneado pelo Estado será, aos poucos, transferido para as mãos de particulares e mesmo dos Estados, após a Proclamação da República (FAUSTO, 2012).

Estes germânicos imigrados para o Brasil se organizavam em comunidades luteranas, em sua maioria, uma mistura de instituição eclesiástica e social, destacando-se a formação de escolas para as primeiras letras e matemática básica, as Deutsche Schule (REHFELTD, 2003). A vida social era regulada pela instituição religiosa (ARANHA, 2002), e, conforme Altmann (1994), as igrejas seriam autônomas da tutela do Estado brasileiro, tendo sua ação voltada para o conforto espiritual e social. Já para Gusso (2001) havia uma clara proibição do Estado Imperial quanto à caracterização destes locais enquanto templos (com cruz e torre), a limitação do reconhecimento do casamento entre imigrantes e seus descendentes (prerrogativa da Igreja Católica e seus registros eclesiásticos paroquiais) e a formação de cemitérios.

\section{AS COMUNIDADES LUTERANAS DE PETRÓPOLIS (RJ) E SANTA ISABEL (ES)}

Na década de 1840 duas colônias na região Sudeste foram criadas pelo governo de Pedro II: uma nas fronteiras da corte, na atual Petrópolis, e outra na Província do Espírito Santo, no atual município de Domingos Martins - respectivamente a Colônia de Petrópolis e a Colônia de Santa Isabel. Cronologicamente os empreendimentos podem ser vistos como contemporâneos e, como veremos a seguir, conectados pelas ações do Estado quanto ao Luteranismo.

A Colônia de Petrópolis tentava redimir a imagem da colonização no Rio de Janeiro, pois em 1820 a imigração de um contingente de colonos de origem suíça para a atual região de Nova Friburgo não obteve sucesso em povoar a região Centro-Norte fluminense:

No ano de 1820 chegou a vanguarda dos colonizadores [ao Rio de Janeiro], constituída por suíços ocidentais católicos e em 1824 os primeiros 324 alemães. De um total de 2.000 imigrantes contratados, 541 morreram durante a viagem ou nos primeiros nove meses após sua chegada ao Rio, enquanto outros 654 logo se dispersaram (FOUQUET, 1974, p. 47). 
Assim, em 1845, sob a direção do major Julius Friedrich Koeler, as cercanias da Fazenda Imperial da Farinha, que daria origem a cidade de Petrópolis, foi habitada por colonos germânicos que, juntamente com a escravaria cedida ao empreendimento, construiriam o Palácio de Petrópolis, o arruamento da colônia e a medição dos prazos a serem vendidos aos primeiros migrados. Além dos recém-chegados, a venda de lotes deu-se ainda aos interessados em habitar a cidade escolhida pela família imperial para fugir do calor e doenças de verão carioca (BARMAN, 2012).

Para autores como Fouquet (1974) e Barman (2012) o motivo da escolha de alemães para a nova cidade de d. Pedro II residia no fato de que, assim como sua mãe, a princesa Leopoldina de Habsburgo da Áustria, estes seriam germânicos. Além disso, conforme o pensamento social da época, estes continham em sua "raça" a capacidade civilizacional tão desejada ao país. Assim, para o seu refúgio de verão, o monarca brasileiro atrelava elementos étnicos, ligados a uma ideia de progresso, às visões subjetivas de um sentimento de pertencimento e família (BARMAN, 2012). Conforme Fouquet (1974), a população inicial de dois mil trezentos e dezoito imigrantes logo seria expandida, seja pela chegada de novos conterrâneos, como pelo crescimento vegetativo destes. Somava-se ainda o fato de que o corpo diplomático estrangeiro, além de nobres do Rio de Janeiro, passou a acompanhar Pedro II em suas estadias em Petrópolis, o que aumentara a população do local e gerava desenvolvimento comercial e de serviços ao local (SCHWARCZ, 1999).

Em 1847, na então Província do Espírito Santo, o governo imperial optara pela fundação de outra colônia de imigrantes germânicos. Com a diminuição da importação de força de trabalho da África, a frágil economia baseada na cana de açúcar, mandioca e pequenas produções de tabaco colapsou, a solução para o fim da estagnação econômica do Espírito Santo seria a agricultura do café com mão de obra imigrada (SILVA, 1995). Concomitante a isso, a baixa densidade populacional, concentrada em três grandes regiões (São Mateus ao Norte, Vitória no Centro e Cachoeiro de Itapemirim na divisa com Campos dos Goitacazes/RJ), era um fator de atraso no desenvolvimento da província (SILVA, 1995), o que seria remediado pelo povoamento do interior (PACHECO, 1978).

A fundação da colônia deu-se em 1847 após a construção de uma estrada ligando a capital à localidade então denominada de Borba, distante duas léguas da vila de Viana, nas cercanias de Vitória. Esta colônia seria seguida, dez anos depois, pela criação uma segunda ocupação, a Colônia Imperial de Santa Leopoldina, também dedicada a receber europeus. Esta segunda experiência, mais bem sucedida que a primeira, seria desmembrada em seguida em 
três grandes municípios que receberiam os imigrantes: Santa Leopoldina para alemães, suíços, holandeses e belgas - a parte mais antiga do empreendimento, datada de 1847; a região leste e mais acidentada, denominada de Santa Maria de Jetibá, devido ao rio homônimo, a partir da década de 1860, para os pomeranos do norte da atual Alemanha; e a região norte, denominada de Santa Teresa, que foi destinada aos imigrantes italianos e uma minoria alemã, apenas nas décadas entre 1870 a 1890 (WAGEMANN, 1949; ROCHE, 1968; RÖLKE, 1996; PEREIRA, 2014).

A inauguração da Colônia de Santa Isabel ocorreu com a chegada de cento e sessenta e três colonos que provinham da região do Hunsrürck e Hesse, no vale do rio Reno. Conforme Seide (1980), em tom de epopeia, os luso-brasileiros de Viana, somados a presença de indígenas, causaram um mal-estar entre os imigrantes. Contudo, "a maior decepção, no entanto, tiveram ao chegar aos seus 'prazos'. Não havia as casas prometidas e, na maioria dos casos, nem os terrenos tinham sido demarcados" (SEIDE, 1980, p. 2). Pacheco (1978) informa que os lotes mediriam duzentas braçadas de frente e seiscentos de fundo. Já Seide (1980) relata apenas que eram de cinquenta e nove hectares. Para ambos os autores, porém, a aclimatação foi difícil, em especial pela alimentação, falta de médicos e a distância com a capital da província.

A situação expressa pelo Ministro Marcos Antonio de Araújo, em 1848, relativa a necessidade de uma lei que regulamentasse a concessão ou venda das terras devolutas, não estava errada (AHI: 202/2/17). A incerteza quanto às demarcações de terras era um fato e, ao longo da imigração (para o caso capixaba), será um dos grandes entraves para a colonização, pois estas péssimas condições eram noticiadas pelos migrados aos seus parentes nas diversas regiões da atual Alemanha (AHI: 402/3/2; FOUQUET, 1974), o que prejudicava novas levas de alemães.

Assim, era preciso resolver os entraves que dificultavam a obtenção de mão de obra germânica para o Brasil. Como expresso nas comunicações entre a legação brasileira em Hamburgo e em Berlim com a Secretária dos Estrangeiros, seria necessário resolver a questão do transporte, da demarcação de terras e sua venda aos imigrantes e o estabelecimento da tolerância religiosa aos luteranos. Tais medidas seriam prementes para a efetivação do empreendimento colonizador, além de ser um atrativo ao concorrido mercado internacional, puxado pelos Estados Unidos e outras nações, na busca pela aquisição da mão de obra germânica (AHI: 202/2/17). 
Brunn (1971) e Fiebig-von Hase (1986) defendem que o problema da falta de regularidade do transporte marítimo só foi resolvido no final do século XIX, com o estabelecimento, por parte da iniciativa de alemães, de empresas regulares destinadas ao transporte entre a América do Sul e a Alemanha, o que ocorreu somente no final do processo de imigração teutônica.

A questão do aceso às terras foi regulamentada por meio do estabelecimento da chamada Lei de Terras de 1850. Esta normativa visava definir as regras de acesso as terras no país, inspirado no Homestad Act dos Estados Unidos, que dispunhas as condições do acesso às propriedades agrícolas nas regiões recém conquistadas do Oeste da América do Norte. No caso brasileiro, excluía-se a figura jurídica da terra devoluta e colocava toda a propriedade desta sob a posse do Estado, cabendo a este cobrar por sua posse (FAUSTO, 2012). Assim, a mera ocupação de terras pelas camadas mais pobres da população, escravos fugidos ou aquilombados era, praticamente, impossível. Este fato acabou por influenciar o acesso à terra pelos imigrantes recém-chegados, dificultando a sua aquisição, ou condicionando o pagamento a contratos de imigração assinados ainda nos portos de embarque da atual Alemanha (WITT, 2001; OLIVEIRA, 2008; NUNES, 2012).

Quanto a tolerância ao Luteranismo, a resposta se deu no nível institucional. A documentação do AHI é reveladora quanto às diretrizes tomadas pelo governo imperial. Em despacho de vinte e dois de outubro de 1858, o então Secretário dos Negócios Estrangeiros, Marques de Olinda, solicitava ao ministro Marcos A. de Araújo que consultasse o Conselho Supremo Eclesiástico de Berlim (a direção do Sínodo Luterano Alemão ou Evangelischen Oberkirchenrat Berlim) acerca da contratação de um pastor a ser enviado para a Colônia de Santa Isabel na província do Espírito Santo em substituição ao recém-falecido reverendo Julius Koenig.

O Estado brasileiro arcaria com as despesas da passagem e oferecia ao contratado o valor de 800 mil réis por ano. A missiva destacava que a contratação se daria aos moldes já realizados anteriormente (AHI: 402/3/2). Ou seja, o prelado luterano falecido não imigrou de livre vontade junto aos demais em 1847, mas era um funcionário pago pelo Estado brasileiro para atender espiritualmente a Colônia de Santa Isabel. Assim, os argumentos de Wagemann (1949), de Roche (1968) e os de Seide (1980) são parcialmente errôneos quanto aos primeiros anos do Luteranismo no Espírito Santo e a sua migração espontânea.

A chegada do pastor a Santa Isabel deu-se em 1858, um ano após a abertura da imigração na região. Conforme fontes luteranas e a bibliografia disponível sobre o prelado, 
ele falecera por meios não conhecidos, sendo indicado que teria sido envenenado por imigrantes católicos (SEIDE, 1980; SANTOS et ali, 1992; MEDEIROS, 1994; PORTAL LUTERANOS, s/d. $)^{8}$. Fim parecido tem um segundo pastor que fora contratado para Santa Isabel em 1859, Konstantin Held. Conforme despacho de dezenove de janeiro de 1860, o Marques de Olinda, solicitava ao ministro Marcos A. de Araújo que esse consultasse novamente Evangelischen Oberkirchenrat Berlim sobre a contratação de um substituto a Held. Autores como Medeiros (1994) e Seide (1980), informam que, assim como Koenig, Held teria sido assassinado por imigrantes católicos. Contudo, a documentação do AHI informa que este último, na verdade, teria falecido em 1859 em decorrência de uma desinteira (AHI: 402/3/6).

Quanto a busca por pastores substitutos para a Colônia de Santa Isabel, o Estado brasileiro comprometia-se em pagar as despesas da viagem, no valor de 600 thalers prussianos, uma remuneração no valor de 800 mil réis por ano pelos serviços religiosos prestados, além do mesmo valor destinado às custas do deslocamento para o retorno à Alemanha, após um prazo de dez anos de trabalho na direção das atividades religiosas da Colônia (AHI: 402/3/2; 402/3/6).

O problema da ausência de serviços luteranos na Colônia de Santa Isabel é resolvido pelo Estado Imperial apenas no meio do ano de 1860. Em resposta ao ofício de três de maio daquele ano, o Marques de Olinda dá ciência acerca da contratação do reverendo Otto Fiege pelas mesmas condições já estabelecidas (AHI: 402/3/6). Fiege chega a Santa Isabel em novembro de 1860 e presta seus serviços religiosos até maio de 1866, sendo substituído em seguida por Miachel Mehl, que pastoreou de 1871 a 1878, e Johannes Schaeffer, pastor entre1878 a 1879 (SANTOS et ali, 1992; PORTAL LUTERANOS, s/d.), estes dois últimos já enviados diretamente pelo Evangelischen Oberkirchenrat Berlim, sem a intermediação do governo brasileiro.

A paróquia luterana de Santa Isabel formou-se em um contexto de conflitos religiosos entre os imigrados alemães católicos e os luteranos. Do total de trinta e nove famílias (cento e sessenta e três imigrados), dezesseis destas eram luteranas. Este fato levou a uma cisão geográfica entre os colonos: os católicos se mantiveram na sede da Colônia, sendo atendidos por padres alemães da Ordem do Verbo Divino. Contudo, os luteranos se

\footnotetext{
${ }^{8}$ Conforme Medeiros (1994, p. 85): “Os católicos criaram toda sorte de obstáculos para que eles [os luteranos] pudessem também ter suas igrejas [...] A morte súbita de alguns pastores deixou até os dias atuais a suspeita de que [,] pelo menos dois deles [,] teriam sido envenenados pelos católicos".
} 
deslocaram para o fundo de um vale, em um campo aberto, batizado de "Campinho", ou Berger, em alemão. A igreja luterana do distrito foi inaugurada apenas em trinta de janeiro de 1887 (SEIDE, 1980; SANTOS et ali, 1992; PORTAL LUTERANOS, s/d.).

Outra colônia que foi provida de serviços religiosos pagos pelo Estado imperial foi a de Colônia de Nova Friburgo, no Rio de Janeiro. Esta foi uma malfadada tentativa de colonização no Centro-Norte fluminense (FOUQUET, 1974). Nova Friburgo foi fundada em 1824, ainda dentro do contexto do Primeiro Reinado, caracterizando-se como uma colônia mista, pois recebera suíços e alemães. O nome Friburgo advém da região de migração suíça Freibug - norte do país helvético. Conforme o Instituto Brasileiro de Geografia e Estatística (IBGE):

A colonização do território pertencente aos municípios de Nova Friburgo e Cantagalo data do reinado de D. João VI, que autorizou, em 1818, a vinda de 100 famílias suíças, oriundas do cantão de Friburgo, para criação de uma colônia. Nomeado inspetor da povoação recém-formada, o Monsenhor Pedro Machado de Miranda Malheiros, instalou a sede da colônia, sob a denominação de Nova Friburgo, em vista da procedência dos colonizadores. As primeiras levas de colonos suíços chegaram, em número de 30 famílias, em fins de 1819 e começos de 1820, depois de serem construídos os edifícios imprescindíveis à vida da colônia. A 3 de janeiro de 1820, considerando o progresso da colônia, baixou o governo alvará que concedia a Nova Friburgo predicamento de Vila e desmembrava suas terras da área de Cantagalo. A instalação da Vila verificou-se aos 17 de abril do mesmo ano, localizando-se a sede na povoação do Morro Queimado. Em 1823, foi incumbido o major George Antônio Scheffer de contratar na Alemanha a vinda de novos imigrantes para o Brasil, destinados às colônias de Leopoldina e Frankenthal, fundadas na Bahia em 1816. Os colonos foram desviados, porém, desses destinos e, por motivos ignorados, encaminhados para Nova Friburgo, onde chegaram a 3 de maio de 1824 (IBGE, s/d, s/p.).

A fundação da Igreja Luterana de Nova Friburgo se deu a partir de um culto ocorrido em quatorze de julho de 1824, meses após data da fundação da Colônia (em três de maio daquele ano). Esta foi servida pelo reverendo Friedrich Oswald Sauerbronn, o qual havia migrado juntamente com seus conterrâneos (WEINGAERTNER, 1997; PORTAL LUTERANOS, s/d.). Weingaertner (1997) defende que Sauerbronn teria sido o primeiro pastor luterano europeu a prestar seus serviços no Brasil e na América Latina. Informa ainda que, como no caso da Colônia de Santa Isabel/ES, os serviços religiosos de Friedrich O. Sauerbronn foram custeados pela Coroa do Brasil, não informando, porém, os valores e condições. A construção do templo em Nova Friburgo deu-se em dois momentos. Em 1827 uma pequena e simplória igreja foi erigida, mas logo desabitada devido a uma ordem de demolição emitida pela direção da Colônia. No ano de 1857 ergueram o segundo e definitivo 
templo, localizado na então Praça do Pelourinho, atual Praça Paissandu (PORTAL LUTERANOS, s/d.).

Devido à idade avançada de Sauerbronn houve a necessidade da escolha de um novo prelado. A sucessão ocorreu em primeiro de julho de 1864, quando o suíço Johann Caspar Meyer, imigrado em 1854 para o Brasil, após anos de auxílio ao pastor Sauerbronn, passou a comandar a igreja (PORTAL LUTERANOS, s/d.).

Já os serviços luteranos na Colônia de Petrópolis estavam associados ao próprio desenvolvimento da imigração na região e da construção do Palácio de Pedro II. O Mordomo deste, Paulo Barbosa, contratou os serviços do Major luterano Koehler. Este foi um exsoldado que servira ao Brasil no contexto da Independência. Ele foi incumbido do povoamento da região do entorno da moradia real e, ao mesmo tempo, para o arruamento da futura colônia e sua consequente habitação. Foram direcionados para os trabalhos em Petrópolis os imigrantes alemães, os escravos que serviram ao Palácio de Santa Cruz e os libertos pela Comissão Mista Brasil-Inglaterra (BARMAN, 20012).

No contexto da criação da estrada que ligava Petrópolis ao Rio de Janeiro - a Estrada da Serra da Estrela - Koehler obteve duzentos e trinta e oito alemães para as obras, os quais foram alocados em prazos vendidos nas cercanias do futuro palácio (SCHWARCZ, 1999; BARMAN, 20012). No ano de 1845 os alemães luteranos perfaziam 37\% da população da Colônia, ou seja, dos 1.921 habitantes, 711 eram confessionais luteranos (PORTAL LUTERANOS, s/d.).

Os primeiros serviços luteranos em Petrópolis foram realizados pelo Pastor Friedrich Ave-Lallemant, pároco da Igreja Evangélica Germânica do Rio de Janeiro. Este visitava e servia os imigrantes em momentos esporádicos e recebia duzentos mil contos de réis do Estado pelos serviços (PORTAL LUTERANOS, s/d.). Conforme Wiemer (1954) e Spliesgart (2006), as suas atividades religiosas eram sucedidas por críticas a Kohler e Paulo Barbosa quanto à direção da Colônia, o que dificultou a manutenção dos serviços luteranos no local.

Sobre a atuação deste prelado, Calmon (1975) informa que algumas cerimônias luteranas por ele dirigidas foram acompanhadas pelo imperador Pedro II. Sobre uma realizada no ano de 1845, o autor descreve: "festa sui generis, com sermão protestante, filarmônica, lágrimas de emoção, flores e palmas campestres, um forte viva a sua majestade o Imperador" (CALMON, 1975/Tomo I, p. 284-285).

A fundação da igreja luterana de Petrópolis ocorreu em vinte e nove de agosto de 1845, sendo esta realizada com a presença de Ave-Lallemant. A igreja, inicialmente, 
funcionou em uma casa e o templo só foi erigido em 1863, ganhando a sua torre apenas no ano de 1903. O primeiro pastor instalado na comunidade luterana da Colônia, em dezenove de junho de 1846, foi Julius Friederich Lippold (PORTAL LUTERANOS, s/d.). De acordo com Wiemer (1954), a personalidade do prelado incomodou tanto aos luteranos, quanto à direção da Colônia. Era comum que ele criticasse ações seculares de membros de seu rebanho e ainda os usos e costumes locais e a escravidão em Petrópolis. Wiemer (1954) ainda destaca que Lippold mantinha relações pessoais com Pedro II, mas sem nenhuma ligação com sua confissão religiosa. Conforme Chavante (2013), estas relações poderiam ser caracterizadas da seguinte forma:

Em sua conhecida dedicação aos estudos das línguas bíblicas, D. Pedro II manteve contato pessoal e prolongado com diversos ministros protestantes, destacando-se nomes como Julius Friedrich Lippold, Filipe Ferdinand Koch, Carl Henning e Christian Frederich Seybold, todos alemães e luteranos, além do Sr. Aklebom, um judeu sueco, com a ressalva de não referir-se o Imperador a Robert Reid Kalley com quem diversas vezes discutiu a língua e a geografia da Bíblia, segundo seus diários. Alfredo de Taunay cita que, em conversa com o casal imperial, ao lembrar um dos professores de línguas orientais já morto, foi aparteado pela imperatriz da seguinte forma: "pena que tivesse sido protestante', ao que replicou D. Pedro II: "Pois então, por esta razão meu bom Lippold há de ir para o inferno? (CHAVANTE, 2013, p. $64)$.

Para Chavante (2013), ações como esta gerariam incômodo junto aos círculos católicos, pois expressavam uma possível defesa da liberdade religiosa defendida, supostamente, pelo Imperador, frente ao catolicismo. Além desta possível correlação, o aprendizado de línguas informa ainda sobre a constante busca por erudição em idiomas e ciências por parte do monarca (SCHWARCZ, 1999; BARMAN, 2012). Ademais, o exceto de Chavante nos permite observar que as relações do imperador Bragança com outros prelados luteranos e tolera aventar que estas excediam a relação que se poderia esperar entre um imperador católico e pastores protestantes.

Quanto ao colégio paroquial (ou Deutsche Evangelische Gemeindeschule) da comunidade, este só foi inaugurado em 1876. Mas, em 1863, o então pastor da comunidade, o alemão Georg Gotlob Ströele, tomou a iniciativa de instalar uma escola comandada por si, em sua residência em Petrópolis, onde se ensinava português e alemão, além de matemática e leitura (KERSTEN, 2005). 
No ano de 1861, a Secretaria dos Estrangeiros fez uma nova solicitação a Marcos A. de Araújo sobre a contratação de pastores junto ao Conselho Supremo Eclesiástico de Berlim. O ofício, datado de dezenove de janeiro daquele ano, informava que um deveria ser enviado para a Colônia de Petrópolis e outro para a Colônia de Mucury (MG) ${ }^{9}$. Os termos de contratação versam sobre o pagamento dos 800 mil contos de réis anuais, mas o valor para os gastos com transporte reduziu-se para apenas 300 thalers prussianos (AHI: 402/3/4).

Em missiva de dois de dezembro de 1861, a Secretaria dos Estrangeiros informa a Marcos de A. Araújo sobre a ciência de sua dificuldade em conseguir novos pastores, em especial devido a "modica quantia de ajuda de custos [para as passagens]", recomendando que as negociações fossem suspensas até nova ordem (AHI:402/3/4). A questão do transporte entre a Europa e a América do Sul mantinha-se como tema ainda não resolvido para a imigração alemã para o Brasil. Contudo, como acabamos de observar, o acesso às terras e a tolerância religiosa já se mostravam menos problemáticas aos imigrantes.

Do exposto até aqui, percebemos como as lideranças religiosas luteranas nas Colônias de Santa Isabel (ES) e Petrópolis (RJ) foram, entre as décadas de 1840-1860, funcionários pagos pelo Estado para servir os imigrantes quanto à sua confissão luterana. $\mathrm{O}$ panorama da ação estatal só será arrefecido, em nossa leitura, por dois fatores: o início de envio de pastores, sem a relação com o Estado brasileiros, pelo Conselho Supremo Eclesiástico de Berlim (o Evangelischen Oberkirchenrat Berlim) ou a organização dos pastores luteranos no Centro-sul do país que resultará na formação dos Sínodos Luteranos no Brasil, a partir de 1880 .

\section{CONCLUSÃO}

Como desenvolvido neste artigo até aqui, defendemos que os anos iniciais do luteranismo no Brasil, especificamente entre as décadas de 1840 e 1860, não foram resultantes da ação individual de prelados voluntários ou apenas das ações de líderes leigos no comando de comunidades religiosas luteranas, como Portella (2006) defende. O Estado foi um agente importante para que esta religião se instalasse no país. Longe de ser o único vetor de implantação do Luteranismo em solo nacional, o governo imperial deve ser considerado como um dos mediadores para a expansão desta religião no século XIX.

\footnotetext{
${ }^{9}$ Colônia fundada por Teófilo Benedito Otoni, em 1851, no Norte do atual estado de Minas Gerais, conforme Rothe (1956).
} 
A ação de contratação de prelados junto ao Conselho Eclesiástico de Berlim nos é indicativo de que a ação estatal do Império no sentido de dar assistência religiosa aos imigrados teve aspectos que em muito se assemelhavam ao regime do Padroado já existente quanto a gestão dos negócios relativos a Igreja Católica Romana. Isto posto, é possível afirmar que houvesse um "Padroado Luterano" e que este tenha sido a escolha do Império para solucionar os problemas gerados pela veiculação da imagem de um país intolerante a não católicos.

O Estado se responsabilizou na contratação e manutenção destes reverendos no intuito de prover os serviços religiosos aos luteranos imigrados, o que auxiliaria na construção da melhoria da imagem do Estado confessional católico brasileiro quanto à tolerância religiosa junto à opinião pública da Alemanha. Tudo isso serviria também para reforçar uma imagem positiva aos que, porventura, remetessem cartas aos conterrâneos na Europa informando sobre a situação das colônias. Além disso, seria mais uma forma de controle estatal nas colônias recém-inauguradas, o que poderia agir como um elemento de controle do governo sobre elas.

Guardando certas semelhanças com o Padroado Católico, o "Luterano" caracterizouse pela busca por prelados para as colônias com imigrantes luteranos. Esta relação era regida pelo pagamento das custas das viagens, pela manutenção de seus serviços e pelo pagamento de seus salários. Isso acabava por condicionar o controle do Estado quanto aos assuntos eclesiásticos luteranos, restringindo-os a um ambiente predominantemente católico sem, porém, constranger a identidade étnica dos imigrados.

Obviamente, nem todas as características das duas instituições são semelhantes. Se no Católico cabia ao monarca a indicação de prelados para determinadas dioceses (expresso no art. 102, parágrafo $2^{\circ}$, da Constituição de 1842), no Luterano isso se dava apenas quando o religioso aceitava as condições de remuneração e de trabalho no Brasil. O controle era menor, porém não inexistente. Enquanto Pedro II tinha direito de intervir nos assuntos da Igreja Católica Romana - como na Questão Religiosa - no Luteranismo percebemos que esse mecanismo intervencionista não seria possível. A posição de chefe de estado e de representante da Igreja Católica não lhe permitia inferir, diretamente, em assuntos da esfera teológica luterana. Cabia-lhe apenas, ou ao Gabinete/Conselheiros, atuar sobre temáticas quanto o casamento misto $^{10}$, o registro de nascimentos e mortes, além da criação de

\footnotetext{
${ }^{10}$ Regulamentado pelo Decreto n. ${ }^{\circ} 1144$ (11 de setembro de 1861). Este conferia efeitos civis aos casamentos de pessoas não católicas. O Decreto tinha um caráter retroativo à sua data e ainda reconhecia os casamentos mistos
}

Fronteiras: Revista de História | Dourados, MS | v. 19 | n. 34 | p. 159 - 181 | Jul. / Dez. 2017 
cemitérios protestantes, reafirmando a esfera de atuação de ambas as religiões sem melindrar as susceptibilidades próprias de cada uma delas.

Se nem todos os elementos permitem uma aproximação maior, os mecanismos, ou princípios empregados, nos permitem analisar como o Estado imperial criou um sistema que operacionalizava a prestação de serviços religiosos luteranos e que tinha por finalidade anular um dos problemas que envolviam a imigração. Assim, observar esta ação intencional do Estado do Brasil nos permite compreender que temas como tolerância religiosa e prestação de serviços a não católicos eram assuntos caros aos que defendiam a imigração como solução econômica e social ao Brasil.

O "Padroado Luterano" permite nos, então, perceber como certas narrativas, em tom de epopeia, foram elaboradas sob dois aspectos quando constituídas na gênese do processo de imigração alemã: o primeiro refere-se a um possível predomínio do tom epopeico quanto a vinda dos prelados, no intuito de negar que, nem sempre, houve uma relação entre a imigração e o acompanhamento dos serviços religiosos a estes imigrados. A segunda leitura possível refere-se à construção de uma memória da negação da relação monetária que mantinha os serviços religiosos luteranos, preferindo a criação de uma tradição (HOBSBAWN \& RANGER, 2012) que a negasse. As duas construções mnemónicas teriam como resultado, em parte, a construção de narrativas, como as descritas por Wagemann (1949), Roche (1968), Seide (1980), Grützmann (2002), no qual os prelados luteranos se constituíam como imigrantes, tais como os membros de seus rebanhos.

Tentando solucionar um dos aspectos que impedia a plena imigração para o Brasil de alemães, o "Padroado Luterano", nas primeiras décadas da imigração no Brasil, foi uma das formas encontradas para tornar o país mais atrativo, e mesmo mais "progressista", aos que deveriam contribuir para a busca da "civilização". Assim, esta ação do Governo imperial não apenas demonstrava sua preocupação com a colonização do país, mas permite nos analisar como ele foi um fator decisivo para a manutenção da Igreja Luterana entre os imigrados, além de configurar-se como um dos meios de expansão deste credo na América do Sul.

\section{FONTES}

Arquivo Histórico do Itamaraty, 402/3/1.

celebrados fora do Brasil. O decreto foi regulamentado dois anos depois, com o Decreto n. 3069 de 1863 (IGLEZIAS, 2010). 
Arquivo Histórico do Itamaraty, 402/3/2.

Arquivo Histórico do Itamaraty, 403/3/3.

Arquivo Histórico do Itamaraty, 402/3/4.

Arquivo Histórico do Itamaraty, 403/3/6.

Arquivo Histórico do Itamaraty, 202/2/17.

\section{REFERÊNCIAS BIBLIOGRÁFICAS}

ALTMANN, W. Lutero e libertação: releitura de Lutero em perspectiva Latino-americana. São Paulo/São Leopoldo: Ática/Sinodal, 1994.

ARANHA, Graça. Canaã. 2. ed. Rio de Janeiro: Ediouro, 2002.

BACHMANN, E. Theodore; BACHMANN, Mercie Brenne. Lutheran Churches in the word. Augsburg/Minneapolis: Lutheran World Federation, 1989.

BARMAN, Roderick J. Imperador cidadão. São Paulo: UNESP, 2012.

BENDIX, Reinhard. Max Weber, um perfil intelectual. Brasília: UNB, 1986.

BRUNN, Gerhard. Deutschland und Brasilien, 1889- 1914. Köln/Wien: Böhlau, 1971.

CALMON, Pedro. História de D. Pedro II. Rio de Janeiro: José Olympio, 1975. Tomo I/IV.

CHAVANTE, Esdras Cordeiro. Do monopólio à livre concorrência: a liberdade religiosa no pensamento de Tavares Bastos (1839-1875). 125f. Dissertação (Mestrado em História). Faculdade de Ciências e Letras de Assis. Universidade Estadual Paulista. 2013.

DELHAES-GUENTHER, Dietrich von. Industrialisierung in Südbrasilien: die deutsche Einwanderung und die Anfänge der Industrialisierung in Rio Grande do Sul. Köln: Böhlau. 1973.

DREHER, A. "Olhando para frente". In: . A presença luterana, 1970. São Leopoldo: Sinodal, 1970, p. 19-22.

DREHER, Martin Noberto. Igreja e germanidade. São Leopoldo/Caxias do Sul: Sinodal/Universidade de Caxias do Sul, 1984.

FAUSTO, Boris. História do Brasil. 14. ed. São Paulo: EDUSP, 2012.

FIEBIG-VON HASE, Ragnhild. Lateinamerika als Konfliktherd der deutsch-amerikanischen Be-ziehungen, 1890-1903. Vom Beginn der Panamerikapolitik bis zur Venezuelakrise von 1902/03. Göttingen: Vandenhoek \& Ruprecht. 1986.

FOUQUET, Carlos. O imigrante alemão. São Paulo/São Leopoldo: Instituto Hans Staden, 1974.

FRANKENBERG, Ruth. "A miragem de uma branquidade não-marcada". In: WARE, Vron (org.). Branquidade: identidade branca e multiculturalismo. Rio de Janeiro: Garamond, 2004, p. 307-338. 
GRANZOW, Klaus. Pomeranos unter dem Kreuz des Südens. Tübingen/Basel: Horts Erdmann Verlag, 1975.

GRÜTZMANN, Geraldo. Centenário da Igreja Luterana em 25 de Julho - Santa Teresa 1902-2002. Santa Teresa: Gráfica São Geraldo, 2002.

GUSSO, S, de F. K. "O início do Protestantismo histórico no Brasil: luta por direitos, evangelismo e educação". Via Teológica. 1 (3), p. 73-87, 2001.

HENNING, M. Ensaios luteranos. São Leopoldo: Sinodal, 1986.

HOBSBAWN, Eric. A Era das revoluções: 1789 - 1848. Rio de Janeiro: Paz e Terra, 1977.

HOBSBAWN, Eric; RANGER, Terrence (Orgs.). A invenção das tradições. São Paulo: Paz e Terra, 2012.

IBGE. Cidades. Nova Friburgo. Disponível em:< http://www.cidades.ibge.gov.br/painel/historico.php?codmun=330340 >. Acesso em 20 de agosto de 2017.

IGLEZIAS, Paola D'Andretta. "A legislação comercial e o movimento de Codificação Civil no Segundo Reinado". In: MOTA, Carlos Guilherme; FERREIRA, Gabriela Nunes. Os juristas na formação do Estado-Nação brasileiro. 1850-1930. São Paulo: Saraiva, 2010, p. 169-186

KERSTEN, Hans (Comp.). Comunidade Luterana em Petrópolis: 160 anos - 1845-2005. Petrópolis: Gráfica Primo's, 2005.

OLIVEIRA, Ryan de Souza. Colonização alemã e poder: a cidadania brasileira em construção (Rio Grande do Sul, 1863-1889). 183 f. Dissertação (Mestrado em História). Programa de Pós-graduação em História. Universidade de Brasília. 2008.

NEGRÃO, Lísias Nogueira. "Pluralismo e multiplicidades religiosas no Brasil contemporâneo". Revista Sociedade e Estado. 23 (2), 2008, p. 261-279.

NUNES, Francivaldo Alves. "A lei de terras e a política de colonização estrangeira na Província do Pará”. Revista Tempos Históricos. 16, 2012, p. 99-126.

ACHECO, Renato. "Os primeiros anos - Conflito nas colônias agrícolas espírito-santenses, 1827-1882". In: Estudos em homenagem a Ceciliano Abel de Almeida. Vitória: Fundação Ceciliano Abel de Almeida, 1978, p. 123-148.

PEREIRA, Rodrigo. "Pomeranos: a trajetória de um povo (Daí Pomerer, daí gan fon ainem folk) e a construção de um passado mitificado entre descendentes de imigrantes pomeranos no Espírito Santo". Revista Interseções. 16 (2), 2014, p. 425-441.

"Entre os Estados Unidos e a Alemanha: o conflito entre vertentes das Igrejas Luteranas no estado do Espírito Santo (1886-1929)". Revista Brasileira de História das Religiões. ANPUH, VIII (22), 2015, p. 223-250. 
PORTAL LUTERANOS. História da Paróquia Evangélica de Confissão Luterana em Domingos Martins/ES. Disponível em: <http://www.luteranos.com.br/conteudo/hi-historiada-paroquia-evangelica-de-confissao-luterana-em-domingos-martins-es $>$. Acesso em 19 de agosto de 2017.

Histórico da Comunidade de Nova Friburgo/RJ. Disponível em:< http://www.luteranos.com.br/conteudo_organizacao/nova-friburgo-rj/historico-dacomunidade-de-nova-friburgo-rj>. Acesso em 20 de agosto de 2017.

PORTELLA, Rodrigo. "Fé, cultura e norma eclesiástica: a gênese da Igreja Luterana no Brasil - organização popular e tutela eclesiástica". Revista Fragmentos de Cultura. 16 (7/8), 2006, p. 593-607.

MEDEIROS, Rogério. Espírito Santo: encontro das raças. Vitória: Reproarta, 1994.

REHFELDT, Mário L. Um grão de mostarda: a história da Igreja Evangélica Luterana do Brasil. Porto Alegre: Concórdia, 2003. v. 1.

ROCHE, Jean. A colonização alemã no Espírito Santo. São Paulo: Difusão Europeia do Livro, 1968.

RODOWICZ-OSWIECIMSKY, Theodor. Die Colonie Dona Francisca in Süd-Brasiliaen. Hamburg: F.H. Nestler und Melle, 1853.

RÖLKE, Helmar Reinhard. Descobrindo raízes: aspectos históricos, geográficos e culturais da Pomerânia. Vitória: UFES/Secretaria de Produção e Difusão Cultural, 1996.

ROTHE, M. (Org.). 100 anos de imigração alemã em Teófilo Otoni. Ijuí: Correio Serrano, 1956.

SANTOS, Ezequiel Sampoaio dos; KILL, Miguel A.; BIGOSSI, Rutiléia; MURARI, Jonas Braz. História, geografia e organização social e política do município de Domingos Martins. Vitória: Brasília Editora, 1992.

SCHWARCZ, Lília Moritz. As barbas do Imperador: D. Pedro II, um monarca nos trópicos. 2. ed. São Paulo: Companhia das Letras, 1999.

SEIDE, Frederico Herdmann. "A colonização alemã no Espírito Santo". In: ACHIAMÉ, Fernando Antônio de Moraes (Org.). Enciclopédia histórica contemporânea do Espírito Santo: Vitória: s/ed., 1980, s/p. (mimeo).

SEYFERTH, Giralda. “ A colonização alemã no Brasil: etnicidade e conflito”. In: FAUSTO, Boris (Org.). Fazer a América. São Paulo: EDUSP, 1999, p. 273-314.

SPLIESGART, Roland. Verbraslianeurung und akkulturation: Deutsche Protestanten im Brasilianischen Kaiserreich amp Bespiel der Gemeiden in Rio de Janeiro und Minas Gerais (1822-1889). Wiesbaden: Harrassowitz Verlag, 2006.

SILVA, Marta Zorzal e. Espírito Santo: Estado, interesse e poder. Vitória: Fundação Ceciliano Abel de Almeida/ Secretaria de Produção e Difusão Cultural, 1995.

SIRIANI, Sílvia Cristina Lambert. "Os descaminhos da Imigração alemã para São Paulo no século XIX - aspectos políticos”. Almanack Braziliense. 2, 2005, p. 91-100. 
SOUZA, Ricardo Alexandre Santos de. "A extinção dos brasileiros segundo o conde Gobineau". Revista Brasileira de História da Ciência. 6 (1), 2013, p. 21-34.

STEYER, Walter O. Os imigrantes alemães no Rio Grande do Sul e o Luteranismo: a fundação da Igreja Evangélica Luterana do Brasil e o confronto com o Sínodo Rio-Grandense 1900-1904. Porto Alegre: Singulart, 1999.

SZMRECSÁNYI, Tamás; LAPA, José Roberto do Amaral (Orgs.). História econômica da Independência e do Império. São Paulo: HUCITEC/FAPESP, 1996.

VENTURA, Margarida Garcez. Igreja e poder no século XV: dinastia de Avis e liberdades eclesiásticas, 1383-1450. Lisboa: Edições Colibri, 1997.

WAGEMANN, Ernst. A colonização alemã no Espírito Santo. Rio de Janeiro: Instituto Brasileiro de Geografia e Estatística, 1949. (Boletim Geográfico, separata dos n ${ }^{\text {os }}$. 68, 69 e 70, nov. e dez. 1948 e jan. 1949).

WEIDUSCHADT, Patrícia. "Os caminhos do Sínodo de Missouri no Rio Grande do Sul: educação e religiosidade (1900-1910)”. História da Educação. 19 (47), 2015, p. 249-269.

WEINGAERTNER, N. XV Concílio Regional da $2^{a}$ Região Eclesiástica da IECLB. 1997 (impresso).

WIEMER, HANS. Geschichter der evangelischen kirchengemeinden Petropolis. In: Fragmentos históricos compilados por ocasião dos congressos em Petrópolis, A.D. 1954. $2^{\circ}$ Congresso Latino-Americano da Federação Luterana Mundial, de 20-23 de Julho; Assembleia do Comitê Latino-Americano da Federação Luterana Mundial, 24-25 de Julho; 13 ${ }^{\text {a }}$ Assembleia do Sínodo Evangélico do Brasil Central, de 23-26 de Julho. Petrópolis: Comunidade Evangélica de Petrópolis, 1954.

WITT, O. L. Igreja na migração e colonização: a pregação itinerante no Sínodo Riograndense. São Leopoldo: Sinodal/IEPG, 1996.

WITT, Marcos Antônio. Política no litoral norte do Rio Grande do Sul: a participação de nacionais e de colonos alemães - 1840-1889. 272 f. Dissertação (Mestrado em História da América Latina). Programa de Pós-graduação em História. Universidade do Vale dos Sinos. São Leopoldo, 2001.

Recebido em: 04/09/2017 Aprovado em: 01/12/2017 